\title{
GENERAL APPROACHES TO THE SUBSTANTIATION OF COMBAT STAFF OF THE ARMED FORCES DEPENDING ON MILITARY-ECONOMIC CAPABILITIES OF THE STATE
}

\author{
Volodymyr Mozharovskyi ${ }^{1}$, Serhii Hodz ${ }^{2}$
}

\begin{abstract}
The article presents the essence and main points of the methodological approach to the substantiation of the optimal combat staff of the armed forces from the perspective of the theory of prevented damage of our troops in the operation and taking into account military-economic capabilities of the state, in particular, financial constraints on the procurement and maintenance of combat means of relevant $j$-types. Inconsistency between tasks scope, which are entrusted to the armed forces (AF) for national security, and level of their combat capability has been and remain one of the fundamental problems that adversely affects the process of their forming, developing, preparing and using. That kind of inconsistency is caused by the impact of some factors, primarily factors characterizing economic-military capabilities of the state. Such factors also involve the capacities of the defense industrial complex in terms of development, production, modernization and providing military units (MU) with weapons and defense equipment (WME). The experience of the troops shows that current financial constraints on the procurement and maintenance of the necessary WME negatively affect the level of MU fighting potential. Thus, the problem and need for the substantiation of optimal combat staff of the AF have been and remain inherent components of the process of their forming and developing taking into account military-economic capabilities of the state. The above defines the relevance of the research under consideration and needs new scientific approaches to the justification of optimal combat staff of the AF, which would ensure guaranteed execution of national security tasks. Based on the analysis of recent research and publications related to the problems of substantiation of the AF staff as well as the assessment of the impact of CP of MU on the level of their combat capability, the paper establishes that available methodologies (methodological approaches) don't specify some issues, including what should the optimal AF combat staff be for guaranteed execution of their intended targets, taking into account the military-economic potential of the state? One of the alternate solutions of the problem is the methodological approach, which is presented in the article, to the justification of the optimal combat staff of the armed forces from the perspective of the theory of prevented damage of our troops in the operation and taking into account military-economic capabilities of the state, in particular, financial constraints on the procurement and maintenance of fighting means of relevant j-types. To get a much better sense of the essence and content of the research subject, the authors define a range of the concepts: "military-economic factors", "prevented damage", "prevented damage theory", "combat potential", "combat capability", "combat staff", "effectiveness of combat use of forces". The authors believe that compared to the available methodological approaches (methods), the methodological approach set out in the article allows:

formalizing the interrelation between the level of combat capability of our forces and the desired value of their prevented damage (CP maintenance) for a defined period of operation, which is achieved by the results of counteraction (fire effect) of fighting means of $j$-types of our troops against the enemy. This enables us to determine the number of combat means of all $j$-types of our troops required at the initiation of the operation, which (taking into account losses for $T$ days of combat activities) ensures the target level of their fighting efficiency;

carrying out the differentiated approach to the determination of the role (contribution) of every kind of our forces in the execution of tasks set in the operation that makes it possible: to calculate the contribution of every $j$-type of combat means (military branch) to the tasks of general damages on enemy and achievement of combat actions
\end{abstract}

\footnotetext{
Corresponding author:

${ }^{1}$ Central Research Institute of the Armed Forces of Ukraine, Ukraine.

E-mail: ovk1923@gmail.com

${ }^{2}$ Central Research Institute of the Armed Forces of Ukraine, Ukraine.

E-mail: vitalikgodz@ukr.net
} 
of the required correlation of parties' $C P$ during $T$ days; to define the contribution of combat means of every $j$ - types (military branch) to reducing the predicted value of the average-daily costs of the original CP of our troops to the acceptable one, the accomplishment of the necessary absolute value of our troops and maintenance of the target level of their combat capability during the $T$-days operation;

improving (based on the indicators of prevented damage) the mathematical model of the optimization problem and elements of the calculation process (algorithm) that allows studying the interdependence between core indicators, which evaluate the effectiveness of combat use of troops during the operation, more specifically.

Prospects for future research are the detailed elaboration of mathematical models and elements of the calculation process (algorithm) for upgrading methodical apparatus, which makes it possible to substantiate the optimal combat staff of the AF required for the successful execution of state security tasks from the perspective of the theory of prevented damage of our troops and taking into account military-economic capabilities of the state.

Key words: combat potential, combat capability, combat staff, combat equipment, prevented damage, mathematical model, optimization problem, methodical apparatus.

JEL Classification: N40, N44, C65

\section{Introduction}

Problem statement in general terms. The capacity of the Armed Forces (AF) to accomplish national security tasks depends on many components. In addition, $\boldsymbol{a}$ combat potential (CP) of the AF, which is considered as a set of material and spiritual factors determining the state and competence of the AF to deliver on the intended outcomes, is a major figure. $\mathrm{CP}$ of the $\mathrm{AF}$ is the central component of the military potential of the state (Combat potential).

It is known that $\mathrm{CP}$ of the military organization (MO) (unit, base, formation, union and the AF as a whole) is an integrated index of the effectiveness that characterizes the maximum number of tasks for the purpose, which $\mathrm{MO}$ is able to perform in the context of typical conditions under the regulatory levels of the capabilities of its command systems, combat (operational), logistics and personnel training (study skills). $152 \mathrm{~mm}$ towed gunhowitzer M1955 (D-20), whose fire power potential is the measurement unit of firepower of different weapons of destruction, is accepted is an accounting unit (AU) of CP of the AF of Ukraine (Mozharovskyi, Godz, 2016).

$\mathrm{CP}$ of MO determines its combat potential - a state which permits $\mathrm{MO}$ to realize its combat capabilities (fighting, fire, maneuver), conduct operations under any conditions and exercise tasks for the purpose intended. Combat potential and combat capabilities of $\mathrm{MO}$ are evaluated by several indicators where the provision of MOs with fighting equipment plays an important role - key samples of weapons and military equipment (WME). This indicator is one of the decisive when substantiating the combat staff - the manning strength of units, formations, unions, which involves organic forces as well as reinforcements that are intended to carry out combat missions. Despite that combat staff of the formations and units is determined by their major (combat) units, combat staff of military branches (forces), uniformed services and the AF as a whole is defined by the available number and combat staff of relevant formations and units and thus, the total number of fighting equipment which is in service of their major units. Consistency of the combat staff with the assigned stare security tasks mainly determines the effectiveness of combat use - a degree of the implementation of combat capabilities of forces, which are engaged in conducting operations (military actions). At the same time, the effectiveness of combat use of forces in the operation is considered as expected target or achievable result upon completion of the operation, which is evaluated by the following core indicators: the extent of damage inflicted on the enemy; the level of survivability (loses of human and material-technical resources shouldn't exceed admissible ones); the volume of spent material and technical resources in the course of operation; completion time (terms) of missions defined by the operation (Mozharovskyi, Hodz, 2018; Mozharovskyi, Hodz, 2017).

The analysis of the principal impact factors on the formation of the combat staff, operational and mobilization readiness of the $\mathrm{AF}$ as well as the conclusions on the assessment of the influence of the level of combat capability of the troops (forces) on the degree of realization of their fighting efficiency shows that there is an inconsistency between the scope of state security tasks entrusted on the AF and the level of their combat capability in the practice of forming, preparing and using the AF. That kind of inconsistency is a consequence of the impact of some factors, in particular, those that characterize the country's military and economic capabilities, namely: macroeconomic indicators of the state (development) of the state economy in a particular period; trends in the military budget of the state; possibilities for the development of military manufacturing in a special period; the cost indicators of maintaining and providing formations (units) with WME and expandable material and technical resources (MTR); industrial capacity on the autonomous production 
of WME and other types of MTR; the development level of science and technology; state of infrastructure and transport capacities of the country; the degree of dispersion, security and vulnerability of important economic entities (Review of force structures in implementation of partnership goal $0028 \ldots$; The Norwegian Navy under the 2017-2020 Long Term Defence Plan; French and German defense...; Le Roux L.; The Voluntary Sector Knowledge Network ... ). There are important factors determining the capabilities of the defense industrial complex (DIC) of the state on the development and launching of production of samples (groups) of WME, modernization and term extension for the operation of the available WME; the existence of WME reserve and WME delivery terms of procurement (additional supply) for military organizations; the conformity of WME samples with current requirements (Poland's Defense Modernization Plan; The Danish Defense Agreement 2013-2017; Bassford, Matt, Kristin Weed, Samir Puri, Gregory Falconer and Anais Reading, 2010).

When conducting operations (combat activities), MO is considered to be combat-effective if its procurement with basic key WME samples is not less than $80 \%$, with others - not less than $60 \%$, provided that the technical condition of these samples meets the established standards. MO is considered to be combat-ineffective if it has lost more than 50\% of its original CP (combat equipment) (Mozharovskyi, Hodz, 2018).

However, the experience of development, preparation and use of the AF shows that the current financial constraints on the procurement and maintenance of the necessary WME negatively affect the level of $\mathrm{MO}$ combat capability. Therefore, the problem and the need to justify a rational (optimal) combat staff of the AF, taking into account the military and economic potential of the state (in particular concerning the elaboration, production, modernization and providing MO with WME) have always been and remain integral components of the process of their forming and developing. The above defines the relevance of the authors' research and needs new scientific approaches to the substantiation of the optimal combat staff of the state AF, which taking into account military-economic factors of the influence on the level of their combat capability, provides a guaranteed execution of the entrusted tasks by the AF.

The purpose of the article is to present the essence and main points of one of such scientific (methodological) approaches.

\section{Analysis of recent research and publications.}

According to the results of recent research and publications related to the problems of substantiation of the rational (optimal) MO combat staff as well as the assessment of the influence of $\mathrm{CP}$ of $\mathrm{MO}$ on the level of their combat capability, one establishes that available methods (methodological approaches) don't come up with responses to the following important questions: first, what is an acceptable level of loses for the AF to execute the tasks on purpose during conducting operations (combat actions)? second, what number of combat means (WME samples), including MOs of relevant military branches (forces), should AF staff have to keep the target level of fighting efficiency of our troops in the $T$-days operation and their capacity to exercises tasks by designation with the necessary effectiveness? third, considering military-economic capabilities of the state, what should the optimal AF combat staff be for the guaranteed performance of the tasks by designation? (Mozharovskyi, Hodz, 2017; Romanchenko, Shuenkin, Mozharovskyi, 2017; Mozharovskyi, Godz, 2018).

To get a well-argued answer to the above questions, the authors propose to use the methodological approach to the substantiation of optimal combat staff of the armed forces from the perspective of the theory of prevented damage of our troops in the operation and taking into account military-economic capabilities of the state (financial constraints on the procurement and maintenance of some j-types).

\section{On the theory of prevented damage of troops in the operation}

The Armed Forces of the state are a complex organizational and technical system, which is considered as a set of interdependent and organically operating elements (sub-systems) according to a unified plan for solving a range of challenges in the context of predetermined factor space (Mozharovskyi, Hodz, 2017). The study of substantiation of the AF combat staff is proposed to be carried out from the perspective of the theory of prevented damage of our troops in the operation, which is comprehended as an integral part of the systems analysis. The authors believe that the above approach makes it possible to conduct morphological, functional and parametric representation of the complex organizational and technical system, to examine all its elements concerning unified positions of the general and basic property of this system (appropriate criterion) holistically - a given coefficient of the combat capability of our troops in the $T$-days operation.

Prevented damage of our troops in the operation means the difference between the loss of our troops, which is potential without taking into account measures on its hindrance or reduction, and the loss taking into account such measures. The theory of prevented damage of our troops in the operation is an integrated system of general knowledge, provisions, mathematical and logical correlations that allows formalizing the relationship between the current and targeted levels of combat capability of the troops, the required volume of their prevented damage 
which is achieved by counteraction - the impact of the troops on the enemy by combat equipment, the damages which have to be inflicted on the enemy to reduce its combat potential, the weakening of the impact on our troops and descent of the average-daily casualties of the original CP of our troops to an acceptable level, as well as the number of combat weapons of all types required at operation's initiation, which provides (taking into account the losses for $T$ days of combat activities) the level of fighting efficiency of troops not lower than targeted one and fulfillment of the tasks defined in the operation with the necessary efficiency (Romanchenko, Shuenkin, Mozharovskyi, 2017; Mozharovskyi, Godz, 2018).

\section{General scope of the methodological approach (calculation process stages)}

Methodological approach to the substantiation of the optimal combat staff of the armed forces of the state envisages the use of indices of output data, which are presented in Table 1, and involves six consecutive and interrelated stages from the perspective of the theory of prevented damage of our troops in the operation and taking into account the state's capabilities (financial restrictions on procurement and maintenance of combat means of some j-types) (Romanchenko, Shuenkin, Mozharovskyi, 2017; Mozharovskyi, Godz, 2018; Mozharovskyi, Hodz, 2018).

The first stage. Evaluation of $\delta \Pi$ - a necessary absolute value of prevented damage (CP conservation) of our troops (combat means of all j-types) (in $\mathrm{AU}$ of CP) for the guarantee of the targeted value of the coefficient of their combat capability $\theta^{\text {вuм }}$ in the $T$-days operation $\theta^{\text {sun }}$.

It is generally thought that one of the possible ways for achieving the value $\delta \Pi$ in the operation, without considering the measures of operational (combat) security, is to reduce the enemy's CP by causing damage, that is, the cut in the original ration of CP parties $\left(\alpha_{0}\right)$ to a level that would meet the targeted $\theta^{\text {вим }}$, and therefore, the current number $N^{\text {вим }}$ of combat means of all $j$-types of our troops whose combat capability (taking into account $\beta_{n}$ ) has to be kept. Increasing the level of fire influence on the enemy will lead to a decline in its CP (combat capabilities) and weaken the impact on our troops. As a result, predicted daily-average relative loses $\beta_{0}$ of our troops will decrease to the level of acceptable daily-average relative losses $\beta_{n}$. This will make it possible to hold combat capability $\left(N^{\text {вим }}>N\right)$ of units of combat means of all $j$-types of our troops.

The physical content of the value $\delta \Pi$ is a difference between required numbers of combat means $N^{\text {вим }}$ whose combat capability has to be kept in the result of increasing fire effect on the enemy to provide (under the conditions $\beta_{n} \cdot T$ ) the targeted value $\theta^{\text {вим }}$ and actual number of combat-effective means $N$ of the available combat staff of our troops (under the conditions $\beta_{0} \cdot T$ ):

$$
\begin{aligned}
& \delta \Pi=\Delta N_{0}-\Delta N_{n}=N^{\text {вии }}-N=\left(\beta_{0} \cdot T-\beta_{n} \cdot T\right) \cdot N_{0}= \\
& =\left[\left(1-\beta_{n} \cdot T\right)-\left(1-\beta_{0} \cdot T\right)\right] \cdot N_{0}=\left(\theta^{\text {вии }}-\theta\right) \cdot N_{0}=\sum_{j=1}^{r} \delta \Pi_{j} .
\end{aligned}
$$

The second stage. Determination of the number of fighting means necessary for the initiation of the operation, taking into account calculated value $\delta \Pi$, which will ensure the target level of combat capability $\left(\theta^{\text {suм }}\right)$ of our troops in the $T$-days operation.

It is believed that achieving the desired level of firepower on the enemy requires an increase in the ammunition expenditure (firing amount), as well as an expansion in the number of combat means of the relevant $j$-type of our troops. In this context, the essential additional number of $j$-type combat means (combat means of all $j$-types) of our troops at the beginning of the operation is calculated by the need for the boost of fire influence on the enemy, the destruction of a certain number of its combat means, thus, by calculated means $\delta \Pi_{j}$ and $\delta \Pi$ which will provide targeted $\theta_{j}^{\text {вuм }}$ and $\theta^{\text {sun }}$ respectively. Consequently, the number $N_{0}^{\text {sun }}$ of combat means of all $j$-types of our troops which is necessary at the operation's outset including $\delta \Pi$ (1) for the achievement of the targeted $\theta^{\text {вим }}$ is as follows:

$$
N_{0}^{\text {вuи }}=\sum_{j} N_{0 j}^{\text {вuи }} \geq N_{0}+\delta \Pi=N_{0}+\left(\Delta N_{0}-\Delta N_{n}\right) ;
$$

and the number $N_{0 j}^{\text {sum }}$ of combat means of $j$-type of our troops necessary at the operation's outset including $\delta \Pi_{j}$ for the achievement $\theta_{j}^{\text {su. }}$ is as follows:

$$
N_{0 j}^{\text {вим }} \geq N_{0 j}+\delta \Pi_{j}=N_{0 j}+\left(\Delta N_{0 j}-\Delta N_{n j}\right) .
$$

The third stage. Calculation of the number of combat means of the enemy $\Delta N_{n p}^{\text {sun }}$, which must be destroyed for the achievement of the necessary absolute value of prevented damage $(\delta \Pi)$ of our troops.

The realization of the value $\delta \Pi$ is conditioned by the destruction of the required number $\Delta N_{n p}^{\text {sun }}=f(\delta \Pi)$ of the enemy's combat means by our troops. At the same time, the formal interrelation between the indices $\Delta N_{n p}^{\text {вuм }}, f(\delta \Pi)$ can be established through $\frac{\beta_{n}}{\beta_{0}}=\frac{N_{n p}}{N_{0 n p}}=1-\frac{\Delta N_{n p}}{N_{0 n p}}$.

An additional number of combat means of j-type and combat means of all $j$-types of our troops, which is necessary at the outset of the operation, will be defined by the demand for increasing fire influence on the enemy, that is the need for the destruction of a targeted number of its combat means $\left(\Delta N_{n p}^{\text {вим }}\right)$, and calculated through an obtained value $\delta \Pi$ :

$$
\Delta N_{n p}^{\text {вим }}=\sum_{i} \Delta N_{n p i}^{\text {вим }}=N_{0 n p} \cdot\left(1-\frac{1-\theta^{\text {suм }}}{\beta_{0}^{\prime} \cdot T}\right)=N_{0 n p} \cdot\left(1-\frac{\beta_{0}^{,} \cdot T-\frac{\delta \Pi}{N_{0}}}{\beta_{0}^{\prime} \cdot T}\right)=N_{0 n p} \cdot \frac{\delta \Pi}{N_{0} \cdot \beta_{0}^{\prime} \cdot T}
$$


Table 1

\section{Output data indices}

\begin{tabular}{|c|c|c|}
\hline Sl.No. & Index & Index essence \\
\hline & $\theta^{\text {вим }}$ & $\begin{array}{l}\text { Composite index (criterion) is a coefficient of combat capability of our } \\
\text { troops (combat means of all } j \text {-types) for } T \text { days of the operation, which is } \\
\text { set by the commander's decision }\end{array}$ \\
\hline 1. & $T$ & Duration (number of days) of the operation \\
\hline 2. & $N_{0 n p}=\sum_{i=1}^{v} N_{0 i n p}$ & $\begin{array}{l}\text { The original CP of the enemy taking into account its combat means of } \\
\text { all } i \text {-types that is defined by the number of tangible combat means or the } \\
\text { number of combat means expressed in the accounting units (AU) of CP }\end{array}$ \\
\hline 3. & $N_{0}=\sum_{j=1}^{r} N_{0 j}$ & $\begin{array}{l}\text { The original CP of our troops taking into account combat means of all } \\
j \text {-types (military branches) that is defined by the number of tangible } \\
\text { combat means or the number of combat means expressed in AU of CP }\end{array}$ \\
\hline 4. & $a_{0}=\frac{N_{0 n p}}{N_{0}}=\frac{\sum_{i} N_{0 i n p}}{\sum_{j} N_{0 j}}$ & General original correlation of parties' CP \\
\hline 5. & $\beta_{0 j}$ & $\begin{array}{l}\text { Average standard relative average daily loses of the combat means of } \\
j \text {-type of our troops due to the enemy's influence }\end{array}$ \\
\hline 6. & $\beta_{0 j}^{\prime}=a_{0} \cdot \kappa_{\phi} \cdot \kappa_{\text {OTB }} \cdot \kappa_{y j} \cdot \beta_{0 j}$ & $\begin{array}{l}\text { The predicted value of the relative average daily expenditures of the } \\
\text { original CP of } j \text {-type of our troops (combat means of } j \text {-type) for T days } \\
\text { of operational activities caused by the combat means of the enemy in } \\
\text { view of the specified value } \beta_{0 j} \text { and coefficients: } a_{0} ; \kappa_{\phi} \text {-forms of the } \\
\text { engagement of own troops; } \kappa_{\text {OTB }} \text { - an operational-tactical significance of } \\
\text { the troops; } \kappa_{y j} \text { - original staffing level of } j \text {-type of troops in accordance } \\
\text { with the staff-basic needs }\end{array}$ \\
\hline 7. & $\beta_{0}^{\prime}=\frac{\sum_{j=1}^{r} N_{0 j} \cdot \beta_{0 j}^{\prime}}{N_{0}}$ & $\begin{array}{l}\text { The predicted value of average daily loses, which is unified for all branches } \\
\text { of our troops (combat means of all } j \text {-types), of their original CP for } \\
T \text {-days of combat activities }\end{array}$ \\
\hline 8. & $\beta_{0}^{,} \cdot T=\frac{\sum_{j=1}^{r} N_{0 j} \cdot \beta_{0 j}^{,}}{N_{0}} \cdot T \leq 1$ & $\begin{array}{l}\text { The predicted value of average daily loses, which is average for all } \\
\text { branches of our troops (combat means of all } j \text {-x types), of their original } \\
C P \text { for } T \text { days combat activities }\end{array}$ \\
\hline 9. & $\begin{array}{c}\Delta N_{0}=N_{0} \cdot \beta_{0}^{,} \cdot T=\sum_{j=1}^{r} \Delta N_{0 j} \\
\Delta N_{0 j}=N_{0 j} \cdot \beta_{0 j}^{,} \cdot T\end{array}$ & $\begin{array}{l}\text { The predicted number of lost } \Delta N_{0} \text { from } N_{0} \text { combat means of all } j \text {-types } \\
\text { of our troops (tangible and in } \mathrm{AU} \text { in } \mathrm{CP} \text { ) under the conditions } \beta_{0}^{\prime} \text { for } T \\
\text { days of combat activities; the number of lost } \Delta N_{0 j} \text { combat means of } j \text {-type } \\
\text { of our troops under the conditions } \beta_{0 j}^{\prime} \text { for - days of combat activities }\end{array}$ \\
\hline 10. & $\begin{array}{c}N=\sum_{j} N_{j}=N_{0}-\Delta N_{0}=N_{0} \cdot\left(1-\beta_{0} \cdot T\right) \\
N_{j}=N_{0 j}-\Delta N_{0 j}=N_{0 j} \cdot\left(1-\beta_{0 j} \cdot T\right)\end{array}$ & $\begin{array}{l}\text { The predicted current number of } N \text { combat-effective means of all } \\
j \text {-types of our troops (tangible ones and in AU of } \mathrm{CP} \text { ) on the results of } \\
\text { the influence of enemy's combat means of all types on them under the } \\
\text { conditions } \beta_{0}^{\prime} \text { for } T \text { days of combat activities; the current number } N_{j} \\
\text { of combat-effective means of } j \text {-type of our troops under the conditions } \\
\beta_{0}^{\prime} \text { for } T \text { days of combat activities }\end{array}$ \\
\hline 11. & $\begin{array}{c}\theta=\frac{N}{N_{0}}=\frac{N_{0}-\Delta N_{0}}{N_{0}}=1-\frac{\Delta N_{0}}{T \cdot N_{0}} \cdot T= \\
=1-\left(\beta_{0}, T\right)=1-\frac{\sum_{j=1}^{r}\left(1-\theta_{j}\right) \cdot N_{0 j}}{N_{0}}\end{array}$ & $\begin{array}{l}\text { The predicted current coefficient value of combat capability (relative } \\
\text { value of } \mathrm{CP} \text { ) of our troops of the available combat staff according to the } \\
\text { actual number } N \text { of combat-effective means of all } j \text {-types of our troops } \\
\text { under the conditions } \beta_{0} \text { for } T \text { days of combat activities }\end{array}$ \\
\hline 12. & $\begin{aligned} & \theta_{j}=\frac{N_{j}}{N_{0 j}}=\frac{N_{0 j}-\Delta N_{0 j}}{N_{0 j}}= \\
= & 1-\frac{\Delta N_{0 j}}{T \cdot N_{0 j}} \cdot T=1-\beta_{0 j} \cdot T\end{aligned}$ & $\begin{array}{l}\text { The predicted current coefficient value of combat capability of } j \text {-types } \\
\text { of troops according to the current number } N_{j} \text { of combat-effective } \\
\text { means of relevant } j \text {-type under the conditions } \beta_{0 j}^{\prime} \text { for } T \text { days of combat } \\
\text { activities }\end{array}$ \\
\hline 13. & $\beta_{n}=\frac{1-\theta^{\text {вим }}}{T} \leq \beta_{0}$ & $\begin{array}{l}\text { Acceptable value of daily average relative loses of the original CP of } \\
\text { combat means of all } j \text {-x types of our troops for } T \text { days of combat activities } \\
\text { for the achievement of the targeted value } \theta^{\text {suм }}\end{array}$ \\
\hline
\end{tabular}




\begin{tabular}{|c|c|c|}
\hline Sl.No. & Index & Index essence \\
\hline 14. & $\beta_{n j}=\frac{\beta_{n}}{\beta_{0}^{\prime}} \cdot \beta_{0 j}$ & $\begin{array}{l}\text { Acceptable value of daily average relative loses of the original CP of } \\
\text { combat means of all } j \text {-x types of our troops for } T \text { days of combat activities } \\
\text { for the achievement of the targeted value } \theta_{j}^{\text {sus }}\end{array}$ \\
\hline 15. & $\theta_{j}^{\text {вим }} \geq 1-\beta_{n j} \cdot T$ & $\begin{array}{l}\text { Targeted value of the coefficient of combat capability of } j \text { military branch } \\
\text { (combat means of } j \text {-type) }\end{array}$ \\
\hline 16. & $\Delta N_{n}=N_{0} \cdot \beta_{n} \cdot T=\sum_{j=1}^{r} \Delta N_{n j}=\sum_{j=1}^{r} N_{0 j} \cdot \beta_{n j} \cdot T$ & $\begin{array}{l}\text { Acceptable number of the lost } \Delta N_{n} \text { for the achievement } \theta^{\text {sun }} \text { from } N_{0} \\
\text { combat means of all } j \text {-types of our troops under the conditions } \beta_{n} \leq \beta_{0} \\
\text { for } T \text { days of combat activities }\end{array}$ \\
\hline 17. & $\begin{array}{l}N^{\text {вим }}=\sum_{j} N_{j}^{\text {вим }}=N_{0}-\Delta N_{n}= \\
=N_{0} \cdot\left(1-\beta_{n} \cdot T\right)=\theta^{\text {вим }} \cdot N_{0}\end{array}$ & $\begin{array}{l}\text { The current number of combat means of all } j \text {-types of our troops whose } \\
\text { combat capability has to be kept for the achievement of the given one } \theta^{\text {вuм }}\end{array}$ \\
\hline 18. & $\theta_{j}^{\text {вuм }} \geq \frac{N_{j}^{\text {вим }}}{N_{0 j}^{\text {вuм }}}=\frac{N_{0 j}^{\text {вuм }}-\Delta N_{n j}}{N_{0 j}^{\text {вuм }}}$ & $\begin{array}{l}\text { The targeted value of the coefficient of the combat capability of } j \text {-type of } \\
\text { troops in view of the necessary number } \theta_{j}^{\text {sun }} \text { of combat means of } j \text {-type } \\
\text { of our troops whose combat capability has to be kept }\end{array}$ \\
\hline 19. & $\theta^{\text {вим }} \geq \frac{N^{\text {вим }}}{N_{0}^{\text {вим }}}=\frac{N_{0}^{\text {вим }}-\Delta N_{n}}{N_{0}^{\text {вим }}}$ & $\begin{array}{l}\text { The targeted value of the coefficient of the combat capability }\left(\theta^{\text {suм }}\right) \text { of } \\
\text { our troops in view of the necessary number }\left(N^{\text {suM }}\right) \text { of combat means of } \\
\text { j-x type of our troops whose combat readiness has to be kept }\end{array}$ \\
\hline
\end{tabular}

However, the outcome of such calculations is the determination of not onlyindices $N_{0}^{\text {вим }}=\sum_{j} N_{0 j}^{\text {вим }}(2)-(3)$ and $\Delta N_{n p}^{\text {suм }}=\sum_{i} \Delta N_{n p i}=f(\delta \Pi)$ (4) but also the number $\Delta N_{n p i}$ of the destroyed combat means of $i$-type of the enemy by combat means of $j$-type of our troops. Wherefore, it is essential to calculate the number of combat means of every $j$-type of our troops necessary at the outset of the operation $-N_{0 j}^{\text {вим }}$ (combat staff of every j-type of our troops).

The fourth stage. Calculation of the current number of $i$-type combat means of the enemy $\left(\Delta N_{n p i}\right)$ which have to be destroyed by combat means of $j$-type of our troops relying on their fighting potential and without considering the value $\delta \Pi$. For this reason, the calculated value $N_{0 j}^{\text {вим }}$ is converted in the tangible combat means $N_{0 j p \ldots .}^{\text {suм }}\left(N_{0 j}^{\text {вuм }} \leftrightarrow N_{0 j p}^{\text {suм }}\right)$. Every tangible combat means has its inherent fighting capabilities (official parameters). Combat means of all $j$-types of our troops can participate in destructing $i$-type combat means of the enemy with some probability $P_{j i}$ of elimination of $i$-type combat means of the enemy (or at least one combat means) from the whole number $N_{0 i n p}$ of units by the tangible combat means of $j$-type of our troops composed of $N_{0 j}^{\text {sun }} \leftrightarrow N_{0 j p}^{\text {sun }}=N_{0 j}+\delta \Pi_{j}$ etc. Taking into account the amount $n_{j i}$ of conducted fire activity of every combat means during $T$ days of military operation, it is calculated the number of destroyed $\Delta N_{n p i}$ from $N_{0 i n p}$ of combat means of $i$-type of the enemy during $T$ days of military actions. The number $\Delta N_{n p i}$ of destroyed $i$-type combat means of the enemy for $T$ days of military operation from the available $N_{0 n p i}$ units in terms of the influence on them by combat means of all types in the composition $N_{0}$ of units of our troops is calculated:

$$
\Delta N_{n p i}=N_{0 n p i} \cdot \beta_{n p i} \cdot T=N_{0 n p i} \cdot P_{n p i}=N_{0 n p i} \cdot\left[1-\prod_{j=1}^{r}\left(1-P_{j i}\right)\right] \cdot
$$

Then, it is calculated the total number of destroyed (without $\delta \Pi$ ) combat means of all types of the enemy from $N_{0} n p$ for $T$ days of military operations:

$$
\Delta N_{n p}=\sum_{i} N_{n p i} \cdot=\sum_{i} P_{n p i} \cdot N_{0 n p i} \cdot
$$

To carry out calculations at the fourth stage, it is also used individual mathematical models [15; [16].

The fifth stage. The comparison of the current number $\Delta N_{n p}=\sum_{i} N_{n p i} \cdot=\sum_{i} P_{n p i} \cdot N_{0 n p i}$. of combat means of all types of the enemy and particularly combat means of every $i$-type of the enemy, which were destroyed by combat means of every $j$-type of our troops, proceeding from their inherent fighting potential (official parameters $R_{1 j i}, n_{j i}$ ) and without considering $\delta \Pi$ with required number of the enemy's destroyed combat means of all types $\Delta N_{n p}^{\text {sun }}=\sum_{i} \Delta N_{n p i}^{\text {sun }}=N_{0 n p} \cdot \frac{\delta \Pi}{N_{0} \cdot \beta_{0}^{\prime} \cdot T}$, which has been calculated at the third stage according to the necessary $\delta \Pi$ of our troops obtained at the first stage. If the condition $\Delta N_{n p} \geq \Delta N_{n p}^{\text {sun }}$ is not performed, there is a need to advance combat capabilities of our troops either by improving military characteristics (modernization) of WME samples or by increasing the number of tangible $N_{0 j \text { р обм }}$ combat means of $j$-types of our troops or scheduling required fire activity $n_{j i}$ to blow up the value $P_{j i}, P_{n p i}$ given $R_{1 j i}, \quad \beta_{n j}, N_{0 j p}$ under unvaried value $N_{0 n p}$. At the same time, the amount $n_{j i}$ of conducted fire activity during the $T$-days operation can be realized by relevant tactical and technical characteristics 
of combat means as well as due to the available reserve of missiles and ammunition of every combat means, which is allocated for disbursements for every day of combat actions. Thus, one gets back to the fourth stage of calculations. Using the method of successive approximations (iteration), it is achieved the condition where $\Delta N_{n p} \geq \Delta N_{n p}^{\text {sun }}$. In this context, it is considered that the troops, according to the level of their fighting efficiency, can complete the tasks defined in the operation with the desired result. Then, the number of combat means of every $j$-type and combat means of all types of our troops (in AU of CP and tangible combat means) required at the operation's initiation is calculated as a total value of their original initial number $\left(N_{0 j}\right),\left(N_{0}\right)$ and an absolute value of prevented damage of every $j$-type of our troops $\left(\delta \Pi_{j}\right)$ based on the results of calculations and an absolute value of prevented damage of combat means of all types of our troops $(\delta \Pi)$. In prospect, it will allow determining what number of different types of combat means should be in the Armed Forces of the state at the beginning of the operation (rational combat staff of the AF) to ensure (taking into account the losses for $T$ days of combat operations) the current coefficient of combat capability $\left(\theta_{n}\right)$ of our troops not lower than the given one $\left(\theta^{\text {sun }}\right)$.

The sixth stage. Statement of the optimization problem and its solution based on the use of the mathematical model for the substantiation of the desirable combat staff of the national AF from the perspective of prevented damage theory of our troops in the operation and taking into account military and economic capabilities of the state (Mozharovskyi, Hodz, 2018; Mozharovskyi, Godz, 2018).

It is generally believed that the coefficient of combat capability $\theta^{\text {sun }}$ of our troops, which is fixed by the commander's decision, in the $T$-days operation is achieved through varying the number of combat means of $j$-type, which are necessary at the operation's onset and similar in terms of their purpose and potential. Combat means of $j$-type can be expressed both in WME hardware $N_{0 p}^{s u n}=\sum_{j=1}^{r} N_{0 j p}^{s u n}$ and AU of CP $N_{0}^{s u n}=\sum_{j} N_{0 j}^{s u n}$. It is important to note that combat means of $j$-types (military branches) can significantly differ not only in terms of the purpose and capabilities (tactical and technical characteristics) as well as cost indicators $c_{j}$. Thus, if it is specified the cost $c_{j}$ of one combat means of $j$-type, the cost of all combat means (weapons pieces) of this type (military branch) $C_{j}$ is interpreted as follows:

$$
C_{j}=c_{j} \cdot N_{0 j p}^{a u n}
$$

and the total cost of combat means of all types of our troops is defined:

$$
C=\sum_{j} C_{j}=\sum_{j} c_{j} \cdot N_{0 j p}^{a u n} .
$$

In the light of the existing trends of the state budget expenditures on defense needs, the option of imposing financial restrictions $C_{\text {обм }}$ on the procurement (purchase, production, modernization) and maintenance (operation, storage, overhaul and repair) of combat means of certain $j$-types (military branches) is not excluded. Therefore, there may be the need to select such combat means of $j$-types numerical strength of which will make it possible to achieve the targeted value of the combat capability $\theta^{\text {sun }}$ of our troops and maximize the damage to be inflicted on the enemy $\max \Delta N_{n p}$.

Consequently, it is considered the optimization problem, which involves determining the possible (limited) number $N_{0 \text { обм }}=\sum_{j} N_{0 \text { обом }}$ of combat means of some $j$-x types (military branches) which would give an option of inflicting maximum damage $\max \Delta N_{n p}$ on the enemy in the $T$-days operation as well as achieving the required degreed of prevented damage $\delta \Pi$ of our troops and thus, the current coefficient of combat capability value of the troops $\left(\theta_{n}\right)$ not lower than given one $\left(\theta^{\text {вun }}\right)$.

It should be pointed out that the problem statement envisages the condition when a certain number of combat means of $j$-type can be purchased and maintained in the context of financial constraints (allocated funds) $C_{\circ \sigma 0}$. There may be also a need to justify the favorable ratio between the number $N_{0 j \text { роб }}$ of actual combat means and the amount $\beta_{n} \leq 0,04$, of firing activity, which is conducted by every combat means of $j$-type of our troops during $T$ days of operational activities to achieve a particular degree (probability $P_{j i}$ ) of destruction of $i$-type combat means of the enemy.

To set the optimization problem, one must also bear in mind that the achievement of the value $\Delta N_{n p}^{s u n}$ is provided by the actions of a possible (limited) number $N_{0 \text { обм }}=\sum_{j} N_{0 \text { jобм }}$ of combat means of all j-types of our troops, which are characterized by the inherent parameters $R_{1 j i}, n_{j i}$, before the operation. In this regard, it is assumed that for maximum damage to the enemy $\max \Delta N_{n p}=\sum \Delta N_{n p i}$, actual combat means $\max \Delta N_{n p}=\sum_{i} \Delta N_{n p i}$ of our troops can act together with some probability $P_{n p i}=1-\prod_{i=1}^{r}\left(1-P_{j i}\right)$ against any combat means of $i$-type of the enemy. Consequently, a value $\Delta N_{n p i}=P_{n p i} \cdot N_{0 n p i}$ can be carried. Calculations results of the actions of tangible combat means of our troops depend both on the values $N_{0 j \text { p oбm }}$ and $R_{1 j i}$, $n_{j i}$. There may also be a need to justify the optimum ratio between the number $N_{0 j \text { p oбm of actual combat }}$ means and the amount $\beta_{n} \leq 0,04$, of firing conducted by each combat means of $j$-type of our troops during $T$ days of military operations to achieve varying degrees (probability $P_{j i}$ ) of destruction of $i$-type combat means of the enemy.

Considering the above, the target function of the optimization problem is as follows: 


$$
\max \Delta N_{n p}=\sum_{i} \Delta N_{n p i}=\sum_{i} P_{n p i} \cdot N_{0 n p i}=\sum_{i} N_{0 n p i} \cdot\left[1-e^{-\frac{\sum_{j=1}^{r} R_{1 j i} \cdot N_{0 j p o b i n} \cdot n j i \cdot\left(1-\beta_{n j}\right)^{r}}{N_{0 n p i}}}\right] .
$$

In addition, there are some restrictions.

The first restriction. Financial resources (funds) $C$, whicharenecessaryfortheprocurementandmaintenance of the possible (limited) number $N_{0 \text { p обм }}=\sum N_{0 j \text { p об, }}$ of actual combat means of all types of our troops, shouldn't exceed allocated financial resources (funds) $C_{\text {oбm }}$. In other words, it is essential to adhere to the condition where $C=\sum_{j} c_{j} \cdot N_{0 j \text { p об } M} \leq C_{\text {oб. }}$. Moreover, the initial (approximate) value of the allocated funds $C_{\text {обм }}$ is decided in the context of overrun of the total cost $C_{0}=\sum_{j} C_{0_{j}}=\sum_{j} c_{j} \cdot N_{0_{j} p}$ of combat means (WME samples) of all types of the original combat staff $N_{0}=\sum_{j} N_{0 j}$ of our troops as well as considering the cost $C_{\delta}=\sum_{j}^{j} C_{\delta_{j}}=\sum_{j} c_{j} \cdot \delta \Pi_{j}=\sum_{j} c_{j} \cdot\left[\left(\beta_{0}-\beta_{n}\right) \cdot N_{0 j p} \cdot T\right]$ of combat means of all $j$-types of our troops, which should be added to their original combat staff for achieving expected absolute value of prevented damage (CP maintenance) $\delta \Pi=\sum_{j=1}^{r} \delta \Pi_{j}$ of our troops in the
T-days operation:

$$
C_{\text {oбin }} \geq C_{0}+C_{\delta}=\sum_{j} C_{0 j}+\sum_{j} C_{\delta j}=\sum_{j} c_{j} \cdot N_{0 j p}+\sum_{j} c_{j} \cdot \delta \Pi_{j} \cdot
$$

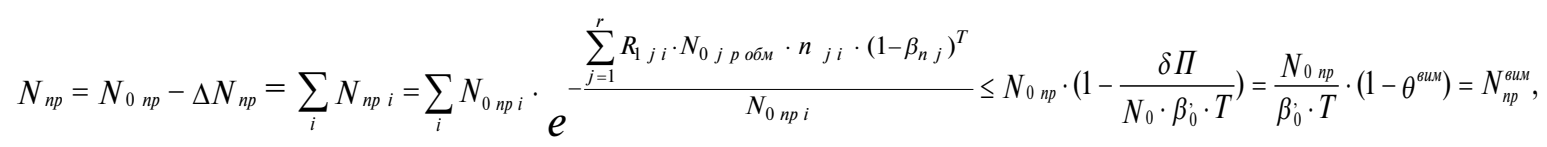

where $N_{0 j p \text { oб } m} \geq 0$ is a value that determines the possible (limited) number of actual $j$-type combat means of our troops with specific fighting potential $\left(R_{1 j i}, n_{j i}\right)$, which can be purchased and maintained using special allocated funds $C_{\text {об̆ }}$.

The above optimization problem (7)-(12) belongs to the nonlinear programming problems. Thus, this problem can be successfully solved through, for example, the method of Lagrange multipliers.

\section{Example of calculations}

The solution of the optimization problem involves an advance consideration of the results of calculations of the rational combat staff of our troops in $T$-days operation. Consequently, according to the calculation results (1)-(6) (the first-fifth stage), one marks that the number of combat means of all types of our troops $N_{0}=585,6 P O>N_{0}^{\text {sun }}=582,3 P O$ that is essential at the beginning of tactical activities guarantees the coefficient value of fighting potential of our troops not lower than given one: $\theta^{\prime}=0,805>\theta^{\text {sun }} \geq 0,80$. The number of combat means (rational combat staff of the
The second restriction. A calculated possible (limited) number $N_{0 \text { робм }}$ of combat means of all $j$-types of our troops before starting the $T$-days operation should provide the current value of the coefficient of combat capability $\theta_{n}$ of the troops not lower than given one $\theta^{\text {вил }}$. Moreover, the actual absolute value of prevented damage of our troops has to be not lower than calculated required absolute value of the prevented damage $(\delta \Pi)$ of the troops. Thus, the condition should be met:

$$
N_{0 \text { р оби }}=\sum_{j} N_{0 j \text { p oб. }} \geq N_{0 p}+\delta \Pi=\sum_{j} N_{0 j p}+\sum_{j=1}^{r} \delta \Pi_{j}
$$

The third restriction. Taking into account the damages which our troops will cause to the enemy during the $T$-days operation with the probability $P_{n p i}$, the current number $N_{n p}=\sum N_{n p i}$ of the enemy's combat means of all $i$-types, whose combat capability will be kept, shouldn't exceed the acceptable number $N_{n p}^{\sigma u n}=N_{0 n p}-\Delta N_{n p}^{s u n} \quad$ of combat-effective means of all $i$-types of the enemy, which can inflict on our troops average-daily relative losses not more than the acceptable losses $\beta_{n}$ in the $T$-days operation (table 1). Thus, one should adhere to the condition:
$A F)$ makes it possible to inflict damage on the enemy at the level $\Delta N_{n p}^{\prime}=713,3 P O \geq \Delta N_{n p}^{\text {sun }}=697,1 P O$, which meets the specified requirements.

In view of the aforesaid, the solution of problem optimization includes:

1) the valuation $\Delta C^{\prime}$ of an additional quantity $\Delta N=\sum_{j} \Delta N_{j}$ of combat means of all types of our troops, which is necessary for the condition's fulfillment $\theta^{\prime} \geq \theta^{\text {sun }}$. It is established that the valuation $\Delta C^{\prime}$ of the additional number of combat means $\Delta N=\sum_{j} \Delta N_{j}$ of all types of our troops required for the condition fulfillment $\theta^{\prime} \geq \theta^{\text {sun }}$, is $\Delta C^{\prime}=\sum_{j} \Delta c_{j}^{\prime}=173,1$ million $\mathrm{UAH}<C_{\delta}=177,9$ million $\mathrm{UAH}$. In other words, $\Delta \mathrm{C}^{\prime}$ is less than the value $C_{\delta}=\sum_{j} C_{\delta j}=\sum_{j} c_{j} \cdot \delta \Pi_{j}-$ cost of combat means of all types of our troops that should be added to their original combat staff $N_{0}$ for the achievement of an essential value $\delta \Pi=\sum_{j=1}^{r} \delta \Pi_{j}$ of the troops in the $T$-days
operation. 
2) the cost calculation $C_{0}$ of the total number of combat means of all types of our troops required at the operation beginning to fulfill the condition $\theta^{\prime} \geq \theta^{\text {вил }}$. Thus, taking into consideration the cost of original number of combat means of all types of our troops $C_{0}=\sum c_{0 j}=517,1$ million $\mathrm{UAH}$, the cost $C_{0}^{\prime}$ of the general number of combat means of all types of our troops needed to start the operations $N_{0}=585,6 P O$ is $C_{0}^{,}=\sum_{j} C_{0 j}=C_{0}+C_{\delta}^{s}=690,2$ million $\mathrm{UAH}<C_{0}^{\text {вим }}=$ $=C_{0}+C_{\delta}=695,0$ million UAH.

3) determining the demand for funds $C$ to purchase and maintain a possible (limited) number $N_{0 \text { оби }}=\sum N_{0 \text { о обм }}$ of combat means of all types of our troops, which shouldn't exceed the allocated funds $C_{o 6 w}$, that is when the condition $C=\sum_{j} c_{j} \cdot N_{0 j \text { р обй }} \leq C_{\text {об̈и }}$ is fulfilled. Considering that $C_{\text {oб }} \geq C_{0}^{\text {sun }}$, from this perspective, one accepts a condition under which $C$ $\geq C_{o 60 \mathrm{~m}}$. According to the results of calculation of the target function through the method of Lagrange multipliers, given the restrictions, we obtain the following data:

$$
C=C_{\text {обм }}=C_{0}^{\text {вим }}=695,0 \text { million } \mathrm{UAH}>C_{0}^{\prime}=690,0 \text { million } \mathrm{UAH} \text {; }
$$$$
N_{0 \text { onm }}=N_{0 \text { oб. }}=593,6 \mathrm{PO}>N_{0}=585,6 \mathrm{PO}>N_{0}^{\text {suu }}=582,3 \mathrm{PO} \text {, }
$$

where $N_{0 \text { onm }}-$ a combat staff of our troops, which is optimal at the outset of operational activities (an optimal number of combat means of all $j$-types) resulting from solving the optimization problem. At the same time, $N_{n p}=488,7 P O<N_{n p}=498,4 P O<N_{n p}^{\text {sun }}=514,6 P O$.

Respectively, indicator values regarding the infliction of the maximum damage on the enemy are as follows: $\max \Delta N_{n p}=723 P O>\Delta N_{n p}^{\prime}=713,3 P O>\Delta N_{n p}^{\text {eun }}=697,1 P O$. Findings provide (including loses during $T=5$ days of operation activities) the current value of the coefficient of combat capability $\theta_{n}$ of our troops not lower than given one: $\theta_{n}=0,816>\theta^{\prime}=0,805>\theta^{\text {вии }} \geq 0,80$.

\section{Conclusions and prospects for future research}

One can note that the problem and need to substantiate the optimal combat staff of the AF of the state (taking into account the financial constraints on the procurement and maintenance of combat means of particular $j$-types) have been and remain an integral component of the process of their formation and development. One of the options for problem solution is the methodological approach, which is presented in the article, to the justification of the optimal combat staff of the armed forces from the perspective of prevented damage theory of our troops in the operation and taking into account military-economic capabilities of the state, in particular, financial limits on the purchase and maintenance of fighting equipment of $j$-types.

Compared to the available methodological approaches (methods), the article's methodological approach allows: formalizing the interrelation between the level of combat capability of our forces and the desired degree of prevented damage (maintenance of $\mathrm{CP}$ ) for a defined period of operation, which is achieved by the results of counteraction (fire effect) of combat means of all types of our troops against the enemy. This makes it possible to determine the number of combat means of all types of our troops required at the initiation of the operation, which (taking into account losses for $T$ days of combat activities) provide the target level of their fighting efficiency, due to the calculated data of the needed absolute value of prevented damage;

carrying out the differentiated approach to the definition of the role (contribution) of every military branch in the execution of tasks set in the operation that enables us: to calculate the contribution of every type of combat means (military branch) to the tasks of general damages to enemy and achievement of the required correlation of parties' $\mathrm{CP}$ for $T$ days of tactical activity; to define the contribution of combat means of every type (military branch) to reducing the predicted number of the average-daily costs of the initial $\mathrm{CP}$ of our troops to the acceptable one, the accomplishment of the required absolute value of prevented damage of our troops (CP conservation) and maintenance (taking into account loses for $T$ days of tactical activities) of the target level of their fighting potential;

improving (based on the indices of prevented damage) the mathematical model of the optimization problem and elements of the calculation process (algorithm) that allows studying the interdependence between core indicators, which evaluate the effectiveness of combat use of troops in the operation, more specifically. In the future, this will allow determining the number of combat means of every type (military branches), which is optimal at the beginning of the operation. The above will ensure (taking into account the losses for $T$ days of combat operations) the required amount of prevented damage and the level of combat capability of our troops not lower than the specified one.

In the authors' view, the application of article's methodological approach in the practice of forming, preparing and using the $\mathrm{AF}$ will enable one to give a substantiated response to the following questions: what the optimal number of combat means (WME samples), as well as $\mathrm{MO}$ of relevant military branches (forces), should the AF have in its composition to keep the targeted level of fighting capability of our troops and their potential to exercise the tasks on purpose with necessary effectiveness during $T$ days operation, taking into account financial constraints?

Prospects for future research are a specification of mathematical models and elements of the calculating process (algorithm) for improving methodical apparatus, which allows substantiating the optimal combat staff of the AF needed for the successful execution of national security tasks from the perspective of the theory of prevented damage of our troops in the operation and considering military and economic potential of the state. 


\section{References:}

Combat potential. Military Encyclopedic Dictionary. Moscow: ONICS 21 Century Publishing House, 2002. 1036 p.

Mozharovskyi, V. M., \& Godz, S. V. (2016). Combat potential as the primary factor of the combat strength of the Ukrainian Forces. Works of University: coll. of sciences. works of NUD of Ukraine named after Ivan Cherniakhovskyi, no 2(68), pp. 279-297.

Mozharovskyi, V. M., \& Hodz, S. V. (2018). The effect of weapons and military equipment on the combat potential and level of combat readiness of troops. S. Direct 24. Safety, Society, Science. International scientific journal published under the auspices of NATO Defence Education Enhancement Program (ISSN 2545-0697). Warszawa, Republic of Poland, no. 1; 01 march.

Mozharovskyi, V. M., \& Hodz, S. V. (2017). Methodological bases for substantiation of rational composition of organizational and technical systems of military designation: Coll. of mater. of the international science-pract. conferences. The International research and practice conference "Modern methods, innovations, and experience of practical application in the field of technical sciences" (General issues of technical sciences). Radom, Republic of Poland, December 27-28, pp. 264-269.

Review of force structures in implementation of partnership goal 0028, preliminary report for consultations with NATO / Ministry of Defense. Sofia, 28 May 2011, 142 p.

The Norwegian Navy under the 2017-2020 Long Term Defence Plan. URL: http://www.navyrecognition.com/ index.php/focus-analysis/naval-technology/4153-analysis-the-norwegian-navy-under-the-2017-2020-longterm-defence-plan.html

French and German defense: The opportunities of transformation. URL: http://www.iris-france.org/wp-content/ uploads/2015/03/IRIS-Note-march-2015-IRIS-SWP.pdf

Poland's Defense Modernization Plan: A Race Against Time. URL: http: //www.avascent.com/2016/09/Poland'sdefense-modernization-plan-race-time

The Danish Defense Agreement 2013-2017.

Le Roux L. The Military Budgeting Process: An Overview (Defense Planning, Programming and Budgeting). URL: ww. sipri.org/contents/milap/milex/le_roux. pdf/download

The Voluntary Sector Knowledge Network, Leadership: Strategic Planning and Strategic Management. URL: http://vskn.ca/lead/strategy.htm

Bassford, Matt, Kristin Weed, Samir Puri, Gregory Falconer and Anais Reading. 2010. Strengths and Weaknesses of the Netherlands Armed Forces. Cambridge: Rand Europe Technical Report.

Romanchenko, I. S., Shuenkin, V. A., \& Mozharovskyi, V. M. (2017). Prevented Damage Theory: Monogram. Lviv: NASW, 244 p.

Mozharovskyi, V. M., \& Godz, S. V. (2018). Methodical aspects of substantiation of the military composition of the armed forces of the state from the standpoint of the theory of prevented damage. International scientifictheoretical. journal of Cybernetics and Systems Analysis, vol. 54, no. 1, pp. 154-167.

Mozharovsky, V. M., \& Godz, S. V. (2016). A mathematical model for determining the magnitude of the possible loss of combat potential of their troops by days of operation that lasts T days. Coll. of sciences. KhNUAF named after Ivan Kozhedub, vol. 4(49), pp. 23-27.

Romanchenko, I. S., \& Mozharovskyi, V. M. (2017). A mathematical model for determining the right amount of destroyed legal enemy units to achieve a given value of the prevented damage to their troops in an operation lasting T days. Coll. of sciences. CMSR of NUD of Ukraine named after Ivan Chernyakhovskyi, no. 1(59), pp. 85-93.

Mozharovskyi, V. M., \& Hodz, S. V. (2018). Substantiation of the optimal composition of organizational and technical systems of military designation: coll. of mater. of international science-pract. conferences. The international research and practical conference "The development of technical sciences: problems and solutions" (General issues of engineering sciences). Brno: Baltija Publishing, the Czech Republic, April 27-28, pp. 165-169.

Mozharovskyi, V. M., \& Godz, S. V. (2018). The Mathematical Model of Substantiation of the Optimal Combat Staff of the Armed Forces of the State from the Standpoints of the Theory of Prevented Damage and Taking into account Economic Factors. International Scientific Theoretic. journal of Cybernetics and Systems Analysis, vol. 54, no. 5, pp. 150-159. 